\title{
About Notiophilus Duméril, 1806 (Coleoptera, Carabidae): Species delineation and phylogeny using DNA barcodes
}

\author{
Michael J. Raupach ${ }^{1}$, Karsten Hannig$^{2}$, Jérome Morinière ${ }^{3}$, Lars Hendrich ${ }^{4}$ \\ 1 Schulstraße 9a, 26180 Rastede, Germany. \\ 2 Bismarckstraße 5, 45731 Waltrop, Germany. \\ 3 Taxonomic coordinator - Barcoding Fauna Bavarica, Bavarian State Collection of Zoology (SNSB - ZSM), Münchhausenstraße 21, 81247 \\ München, Germany \\ 4 Sektion Insecta varia, Bavarian State Collection of Zoology (SNSB - ZSM), Münchhausenstraße 21, 81247 München, Germany
}

http://zoobank.org/C63A90C7-9612-4DC1-AB8B-8E87BA515B38

Corresponding author: Michael J. Raupach (michael.raupach@rub.de)

Received 25 March 2019

Accepted 7 May 2019

Published 29 May 2019

Academic editor:

James Liebherr

\section{Key Words}

Colonisation

Europe

Cytochrome $c$ oxidase subunit I

German Barcode of Life (GBOL)

Mitochondrial DNA

Nebriinae

Zoogeography

\begin{abstract}
The genus Notiophilus Duméril, 1806 is a distinctive taxon of small, diurnal and morphologically similar beetles exhibiting large eyes and widened second elytral intervals. In this study we analysed the effectiveness of DNA barcodes to discriminate 67 specimens that represent 8 species of Notiophilus from Central Europe. Interspecific K2P distances below 2.2\% were found for $N$. biguttatus (Fabricius, 1779) and N. quadripunctatus Dejean, 1826, whereas intraspecific distances with values $>2.2 \%$ were revealed for $N$. rufipes Curtis, 1829. An additional phylogenetic analysis of all available species revealed a close relationship of $N$. directus Casey, 1920, N. semistriatus Say, 1823, N. simulator Fall, 1906 and N. sylvaticus Dejean, 1831, possibly indicating a radiation of these species in North America. Low support values of most other nodes, however, do not allow additional phylogenetic conclusions.
\end{abstract}

\section{Introduction}

The Carabidae or ground beetles are a huge cosmopolitan family with an estimated number of more than 40,000 species worldwide (Lindroth 1985, Lorenz 2005). As part of its subfamily Nebriinae, the tribe Notiophilini Motschulsky 1850 is a relatively small taxon that includes only one genus: Notiophilus Duméril, 1806. Nevertheless, this genus is one of the more distinctive genera of Carabidae. With a body length of less than $7 \mathrm{~mm}$, species of Notiophilus are small carabids that can be easily recognised by the enormous eyes and furrowed frons, their extremely uniform general habitus with narrow, parallel-sided elytra, as well as by the characteristic dilated second elytral interval ("Spiegelfeld") that can be broad as the $3^{\text {rd }}$ plus $4^{\text {th }}$ interval or broader (Fig. 1) (e.g. Lindroth 1961-1969). Many species exhibit wing dimorphism with macropterous (long-winged) and brachypterous (short-winged) morphs (Lindroth 1986, Chapman et al. 2005). Typically, beetles of this genus are diurnal, sun-loving insects and very rapid in their movements. They are visual carabids, preying upon mites, springtails and other small arthropods (e.g. Anderson 1972, Bauer 1981, Ernsting and Mulder 1981, Ernsting et al. 1992). To date, 57 species have been described from the Palearctic, Oriental, Nearctic and Neotropical regions (Barševskis 2011, Bousquet 2012, Löbl and Löbl 2017). For Europe, 14 species are recorded (Barševskis 2007), whereas 9 are known from Germany and Central Europe (Müller-Motzfeld 2006, Trautner et al. 2014). Thanks to the thorough 


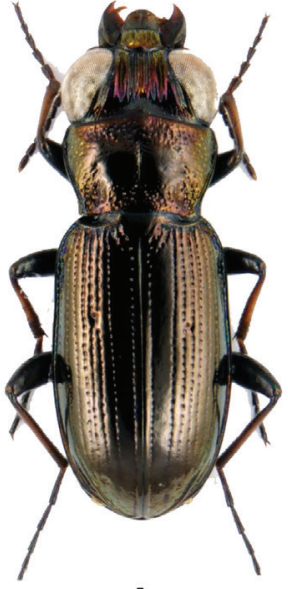

A

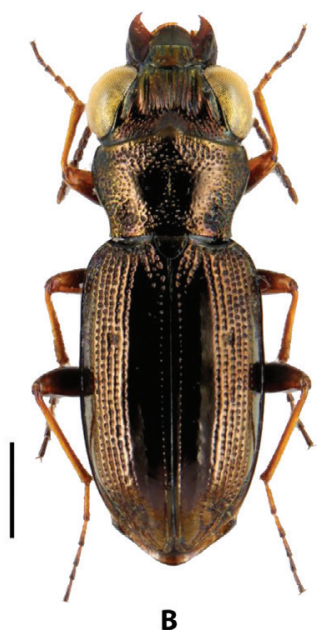

B
Figure 1. Two representative species of the genus Notiophilus amongst those analysed in this study: A: Notiophilus germinyi Fauvel in Grenier, 1863 and B: Notiophilus rufipes Curtis, 1829. Note the characteristic different size of the second elytral intervals ("Spiegelfeld") for both beetle species. Scale bars $=1 \mathrm{~mm}$. Source of photos: http://www.eurocarabidae.de/ (access date: 2019-01-15).

studies of Arvīds Barševskis (Latvia), our knowledge about the biogeography and taxonomy of this genus has increased significantly in recent years (e.g. Barševskis 2001, 2007, 2009, 2011, 2012). Based on the fact that the largest diversity of species and the highest number of endemics are found in Asia, the central part of this continent is hypothesised as the centre of origin of Notiophilus, followed by a subsequent colonisation of Europe, North Africa and North America (Barševskis 2007). In terms of the phylogeny of this genus, however, no analysis has been performed to date.

As noted, species of Notiophilus are remarkably similar in habitus and display a considerable individual variation, making identification difficult (e.g. Lindroth 1961-1969, Hannig 2005, Heijermann and Aukema 2014). Consequently, molecular methods may represent another useful alternative for correct specimen identification. Recently, the analysis of DNA sequence data, in particular the use of an approx. 660 base pair (bp) fragment of the mitochondrial cytochrome $c$ oxidase subunit 1 (COI), has been proposed as the marker of choice, as a so-called "DNA barcode", for specimen identification (Hebert et al. 2003a, Hebert et al. 2003b). DNA barcoding relies on the assumption that the observed interspecific genetic variation exceeds the intraspecific variation to such a proportion that a clear gap exists. As a consequence, unidentified individuals can be assigned correctly to their species (Hebert et al. 2003a, Hebert et al. 2003b). Not surprisingly, DNA barcoding has been criticised from its beginning, for example for the inappropriate use of neighbour-joining trees for analysis or the application of fixed distance thresholds (Will and Rubinoff 2004, Goldstein and DeSalle 2010, Collins and Cruickshank 2013). Nevertheless, nu- merous studies clearly demonstrate the usefulness of DNA barcoding, in particular for insects (e.g. Hausmann et al. 2011, Park et al. 2011, Morinière et al. 2014, Schmidt et al. 2015, Havemann et al. 2018). Thus, the compilation of comprehensive and representative DNA barcode libraries represents an essential step for subsequent studies, for example, biodiversity assessment studies via metabarcoding based on modern high-throughput sequencing technologies (e.g. Yu et al. 2012, Cristescu 2014, Brandon-Mong et al. 2015, Porter and Hajibabaei 2018). Despite the high number of described species, however, the number of studies that tested the efficiency of DNA barcodes for species identification of ground beetles is still low (Greenstone et al. 2005, Maddison 2008, Raupach et al. 2010, Woodcock et al. 2013, Pentinsaari et al. 2014, Hendrich et al. 2015, Raupach et al. 2016, Raupach et al. 2018).

As part of our efforts in building a comprehensive DNA barcode library of ground beetles of Germany, we analysed the quality of DNA barcodes to discriminate Central European species of the carabid genus Notiophilus. Furthermore, we reconstructed the phylogeny of this small but charismatic carabid genus for the first time, with a focus on the zoogeographic distribution of the analysed species.

\section{Material and methods}

\section{Sampling of specimens}

All analysed ground beetles were collected between 2005 and 2017 using various classical sampling methods (i.e. hand collecting, pitfall traps) and stored in ethanol (96\%). The analysed specimens were identified by two of the authors (KH, MJR) using the key provided in Müller-Motzfeld (2006). In total, 35 new barcodes were generated. For our analysis, we also included 32 DNA barcodes of a previous study (Hendrich et al. 2015). As a result, the complete dataset consisted of 67 DNA barcodes. Most beetles were collected in Germany $(n=61,91 \%)$, but for comparison, some specimens were also included from Austria $(n=3,4 \%)$, Belgium $(n=2,3 \%)$ and Slovenia $(n=1,2 \%)$. Our analysis covers eight of the nine species recorded from Germany (88.9\%): Notiophilus aestuans Dejean, 1826, N. aquaticus (Linnaeus, 1758), N. biguttatus (Fabricius, 1779), N. germinyi Fauvel in Grenier, 1863, N. palustris (Duftschmid, 1812), N. quadripuncatus Dejean, 1826, N. rufipes Curtis, 1829 and N. substriatus Waterhouse, 1833. Only specimens of the rare species $N$. laticollis Chaudoir, 1850 were missing (see Trautner et al. 2014). The number of analysed specimens per species ranged from a minimum of 3 (N. quadripunctatus) to a maximum of 16 ( $N$. biguttatus).

DNA barcode amplification, sequencing and data depository

Laboratory operations were carried out, following standardised protocols for COI amplification and sequencing 
(Ivanova et al. 2006, deWaard et al. 2008), at the Canadian Center for DNA Barcoding (CCDB), University of Guelph, the molecular labs of the Zoologisches Forschungsmuseum Alexander Koenig in Bonn and/or the working group Systematics and Evolutionary Biology at the Carl von Ossietzky University Oldenburg, Germany. Representative photos from each studied beetle were taken before molecular work was performed. One or two legs of one body side were removed for the subsequent DNA extraction which was performed using NucleoSpin Tissue Kit (Macherey-Nagel, Düren, Germany), following the extraction protocol.

Detailed information about used primers, PCR amplification, and sequencing protocols can be found in a previous publication (see Raupach et al. 2016). All purified PCR products were cycle-sequenced and sequenced in both directions at a contract sequencing facility (GATC, Konstanz, Germany), using the same primers as used in PCR. Double stranded sequences were assembled and checked for mitochondrial pseudogenes (numts) by analysing the presence of stop codons, frameshifts, as well as double peaks in chromatograms with the Geneious version 8.1.9 programme package (Biomatters, Auckland, New Zealand) (Kearse et al. 2012). Routinely, BLAST searches (nBLAST, search set: others, programme selection: megablast) were performed to confirm the identity of all new sequences as ground beetle barcodes, based on already published sequences (high identity values, very low E-values).

Comprehensive voucher information, taxonomic classifications, photos, DNA barcode sequences, primer pairs used and trace files (including their quality) are publicly accessible through the public dataset "DS-BANOT" (Dataset ID: dx.doi.org/10.5883/DS-BANOT) on the Barcode of Life Data Systems (BOLD; www.boldsystems.org) (Ratnasingham and Hebert 2007). All new barcode data have been deposited in GenBank (accession numbers: MK567377-MK567411).

\section{DNA Barcode analysis: Species identification}

The analysis tools of the BOLD workbench were employed to calculate the nucleotide composition of the sequences and distributions of Kimura-2-parameter distances (K2P; Kimura 1980) within and between species (align sequences: BOLD aligner; ambiguous base/gap handling: pairwise deletion). All barcode sequences became subject of the Barcode Index Number (BIN) analysis system, implemented in BOLD that clusters DNA barcodes in order to produce operational taxonomic units that typically closely correspond to species (Ratnasingham and Hebert 2013). A threshold of 2.2\% was applied for a rough differentiation between intraspecific and interspecific distances based on Ratnasingham and Hebert (2013). These BIN assignments on BOLD are constantly updated as new sequences are added, splitting and/or merging individual BINs in light of new data (Ratnasingham and Hebert 2013).

In addition, all sequences were aligned using MUSCLE (Edgar 2004) and analysed using a neighbour-join- ing cluster analysis (NJ; Saitou and Nei 1987) based on K2P distances with MEGA X (Kumar et al. 2018) in order to visualise the DNA barcode divergences and species cluster. As outgroup taxa we used three barcode sequences of Nebria brevicollis (Fabricius, 1792) (accession numbers: KM451780, KM452043, KM452651). Non-parametric bootstrap support values were obtained by re-sampling and analysing 1,000 replicates (Felsenstein 1985) implemented in MEGA X. For species pairs with interspecific distances $<2.2 \%$, maximum parsimony networks were constructed with TCS 1.21, based on default settings (Clement et al. 2000) as part of the software package PopART v.1.7 (Leigh and Bryant 2015) after an alignment using MUSCLE (Edgar 2004). Such networks allow the identification of possible haplotype sharing between species as a consequence of recent speciation or on-going hybridisation processes.

\section{DNA Barcode analysis: Phylogenetic applicability}

As part of our phylogenetic study, we used one representative sequence per analysed species, namely a sequence of the most abundant haplotype. Furthermore, we added sequences of all additional species available at BOLD with a length of at least 500 base pairs (bp), following the same procedure if more than one sequence was given: Notiophilus aeneus (Herbst, 1806), N. borealis Harris, 1869, N. directus Casey, 1920, N. reitteri Spaeth, 1900, N. semistriatus Say, 1823, N. simulator Fall, 1906 and N. sylvaticus Dejean, 1831. Five CO1 sequence of the genus Nebria Latreille, 1802 (N. brevicollis (Fabricius, 1792) (KM451780), N. frigida R.F. Sahlberg, 1844 (KU875532), N. metallica Fischer von Waldheim, 1822 (KU875541), N. nivalis Paykull, 1790 (KU875543) and N. salina Fairmaire \& Laboulbène, 1854 (KM444378)) were used as outgroup taxa. In total, this dataset consisted of 20 sequences. All sequences were aligned using MUSCLE with default settings (Edgar 2004).

The accuracy of phylogenetic reconstructions depends on various factors, e.g. sequence quality, the correct identification of homologous sites, the absence of heterotachy or, in particular, substitution saturation (Xia 2009). In the extreme case that sequences have experienced full substitution saturation, the given similarity between the sequences will depend entirely on the similarity in nucleotide frequencies and often do not reflect their phylogenetic relationships (e.g. Steel et al. 1993, Xia et al. 2003). As a consequence, fast evolving protein coding genes, such as COI, cannot be used for phylogenetic analysis that focus on deep and old branches (e.g. Wetzer 2002, Goetze 2003, Maddison et al. 2014), but can be useful for the study of more recent phylogenetic events on species level (e.g. Klopfstein et al. 2010, Matzen da Silva et al. 2011, Dai et al. 2012). Therefore, DAMBE 7.0.28 (Xia 2018) was used to check if the COI dataset of Notiophilus was subject to saturation following the Xia approach (Xia 2009). Saturation plots were made using the number of transitions and transversions plotted against patristic distances ( $p$-distances). 
Phylogenetic relationships were analysed under the maximum likelihood criterion using IQ-TREE 1.6.8 (Nguyen et al. 2015). The best model nucleotide substitution was determined based on the Bayesian Information Criterion (BIC) with Modelfinder (Kalyaanamoorthy et al. 2017). In order to assess nodal support, 10,000 ultrafast bootstrap replicates (Hoang et al. 2018) and 10,000 replicates of a SH-aLRT test (Guindon et al. 2010) were performed. Ultrafast bootstrapping (UFBoot) has been demonstrated to be largely unbiased compared to standard or alternative bootstrapping, whereas SH-aLRT values have been shown to be as conservative as standard non-parametric bootstrap values (Minh et al. 2013). Typically, nodes with support values of UFBoot $\geq 95$ and SH-aLRT $\geq 90$ were considered as very robust and values $\geq 80 \%$ as robust (Minh et al. 2013, Hoang et al. 2018). Following Barševskis (2007), we added biogeographic information for each analysed species.

\section{Results}

\section{DNA Barcode analysis: Species identification}

Overall, 67 DNA barcode sequences were analysed for eight of the nine species of the genus Notiophilus from Germany. Fragment lengths of the analysed DNA barcode fragments ranged from 549 to $658 \mathrm{bp}$. As is typically known for arthropods, a high AT-content was found for the DNA barcode region: the mean sequence compositions were $\mathrm{A}=28 \%, \mathrm{C}=16.3 \%, \mathrm{G}=17.3 \%$ and $\mathrm{T}=38.4 \%$. Intraspecific K2P distances within a genus ranged from zero to a maximum of $3.62 \%$ ( $N$. rufipes), whereas interspecific distances within the analysed genus had values between 0.62 and $10.22 \%$ (Table 1). The lowest interspecific distances of distinct barcode clusters were found for $N$. biguttatus and $N$. quadripunctatus with values ranging from $0.49 \%$ to $0.82 \%$ (Table 1 ). As a result, both species became subject to the same BIN (AAO0964). In contrast to this, maximum intraspecific pairwise distances $>2.2 \%$ were found for $N$. rufipes $(3.62 \%)$, resulting in two BINs (AAX5571, AAC7024) for this species (Table 1). Unique BINs were identified for the remaining five species (63\%).

The NJ analyses, based on K2P distances, revealed non-overlapping clusters with bootstrap support values of $100 \%$ for six species $(75 \%)$. Nodal support values below $85 \%$ were found for $N$. biguttatus and N. quadripunctatus (Fig. 2). A detailed topology is presented in the supporting information (Suppl. material 1). Our statistical maximum parsimony analysis indicated closely related haplotypes for the studied specimen of $N$. biguttatus $(n=16)$ and $N$. quadripunctatus $(n=3)$ (Fig. 3). We identified three different haplotypes with one dominant haplotype (h1) for $N$. biguttatus (Fig. 3), whereas only one haplotype (h1*) was found for all analysed beetles of $N$. quadripunctatus ( $n=$ $3)$. However, this haplotype is separated from haplotype $\mathrm{h} 1$ and $\mathrm{h} 2$ of $N$. biguttatus only by five additional mutational steps (Fig. 3). Two distinct monophyletic lineages, in combination with high distances, were found for $N$. rufipes (Figs 2, 4, Table 1).

\section{DNA Barcode analysis: Phylogenetic applicability}

The test of substitution saturation revealed that the observed index of substitution saturation (Iss: 0.22) for the alignment was significantly lower than the corresponding critical index substitution saturation (Iss.c (symmetrical tree): 0.74; ISS.C (asymmetrical tree): 0.54), indicating that there was no or little saturation in the dataset (Suppl. material 2).

Modelfinder revealed the GTR $+\mathrm{F}+\mathrm{R} 3$ model as the optimal nucleotide substitution model for our dataset with the following rate parameters: nucleotide frequencies $\mathrm{A}$ : 0.29, C: 0.16 , G: 0.17, T: 0.38; substitution rates RAC: 0.01, RAG: 40.39, RAT: 21.52, RCG: 1.45, RCT: 98.02, RGT: 1; model of rate heterogeneity: FreeRate with 3 categories: category 1 with a relative rate $=0.06$ and a proportion of 0.69 , category 2 with a relative rate $=2.02$ and a proportion of 0.27 and category 3 with a relative rate $=$ 12.74 and a proportion of 0.03 ).

Table 1. Molecular distances based on the Kimura 2-parameter model of the analysed specimens and species of the genus Notiophilus. Divergence values were calculated for all studied sequences, using the Nearest Neighbour Summary implemented in the Barcode Gap Analysis tool provided by the Barcode of Life Data System (BOLD). Align sequencing option: BOLD aligner (amino acid based HMM), ambiguous base/gap handling: pairwise deletion. ISD = intraspecific distance. BINs are based on the barcode analysis from 18-11-2018. Species with maximum intraspecific distances $>2.2 \%$ and species pairs with interspecific distances $<$ $2.2 \%$ are marked in bold.

\begin{tabular}{lcccccc}
\hline \multicolumn{1}{c}{ Species } & $\boldsymbol{n}$ & Mean ISD & Max ISD & BIN & Nearest Species & Distance to NN \\
\hline Notiophilus aestuans Dejean, 1826 & 4 & 0.24 & 0.48 & ACB8850 & N. aquaticus & 7.04 \\
Notiophilus aquaticus (Linnaeus, 1758) & 10 & 0.58 & 1.12 & AAY5028 & N. aestuans \\
Notiophilus biguttatus (Fabricius, 1779) & $\mathbf{1 6}$ & $\mathbf{0 . 2 2}$ & $\mathbf{0 . 7 7}$ & AAO0964 & N. quadripunctatus & $\mathbf{0 . 6 2}$ \\
Notiophilus germinyi Fauvel in Grenier, 1863 & 5 & 0.43 & 0.92 & AAY5659 & N. rufipes \\
Notiophilus palustris (Duftschmid, 1812) & 10 & 0.26 & 1.11 & AAX5556 & N. aquaticus & 9.17 \\
Notiophilus quadripunctatus Dejean, 1826 & $\mathbf{3}$ & $\mathbf{0}$ & $\mathbf{0}$ & $\mathbf{A A O 0 9 6 4}$ & N. biguttatus & $\mathbf{0 . 6 2}$ \\
Notiophilus rufipes Curtis, 1829 & $\mathbf{8}$ & $\mathbf{1 . 5 5}$ & $\mathbf{3 . 6 2}$ & AAX5571, AAC7024 & N. palustris & $\mathbf{9 . 2 4}$ \\
Notiophilus substriatus Waterhouse, 1833 & 11 & 0.08 & 0.31 & ACC3407 & N. aquaticus & 7.73 \\
\hline
\end{tabular}




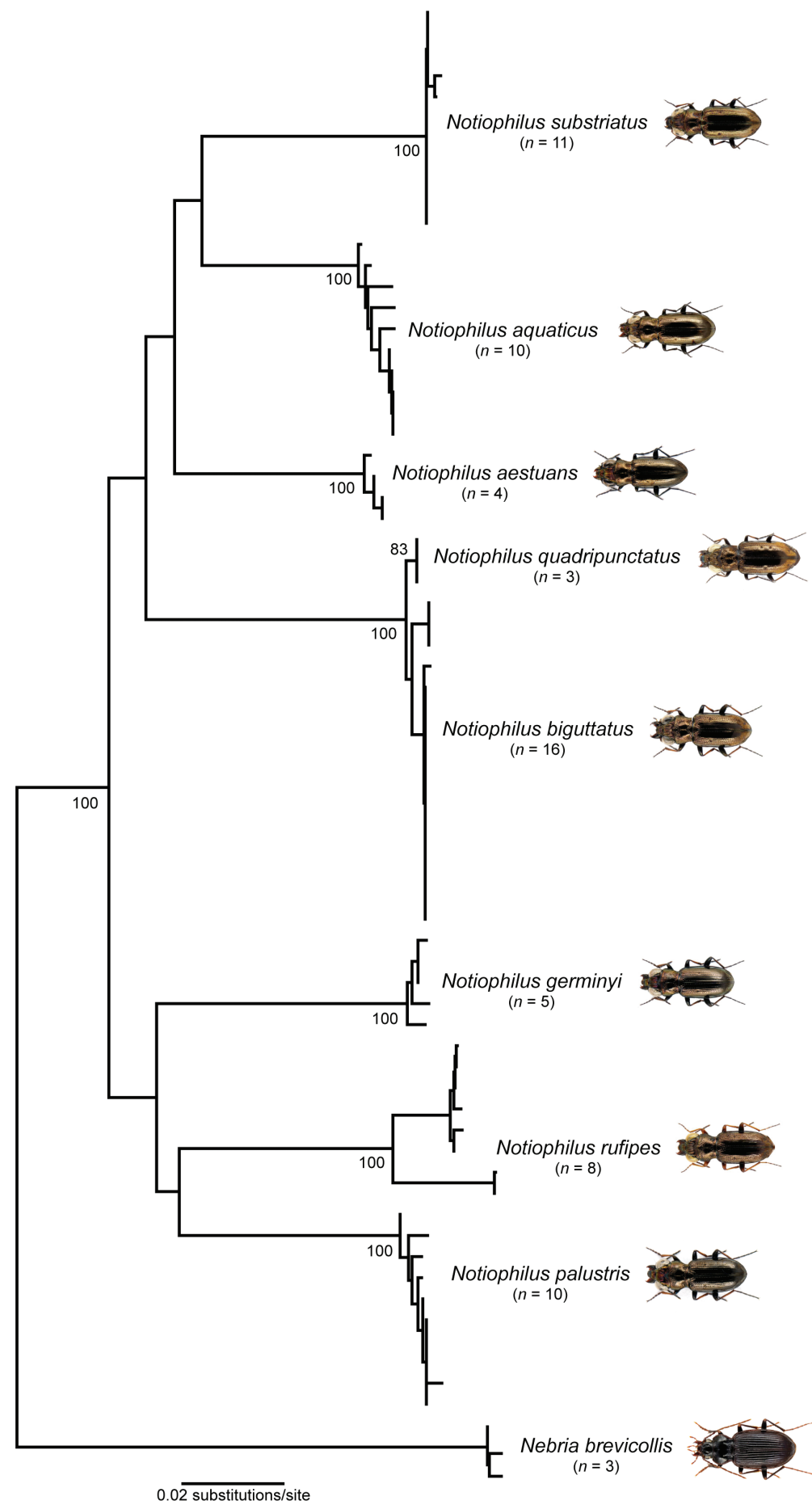

Figure 2. Neighbour joining (NJ) topology of the analysed ground beetle species of Notiophilus, based on Kimura 2-parameter distances. Numbers next to nodes represent non-parametric bootstrap values $>90 \%$ (1,000 replicates). Source of photos: http://www. eurocarabidae.de/ (access date: 2019-01-15).

The results of the phylogenetic analysis are visualised in Figure 5. High nodal support $>90 \%$ was found for five nodes only, whereas medium support (SH-aLRT: $80-90 \%$; UFBoot: $80-90 \%$ ) was revealed for two nodes. All other nodes had support values $<80 \%$, indicating low support. High nodal support values revealed that $N$. aeneus represents the sister taxon to all other analysed Notiophilus species. All other taxa are part of two clades: one clade included N. biguttatus and N. quadripunctatus $(100 \% / 100 \%)$; all other species were found in a second clade with medium support (87.4\%/85\%). Furthermore, high nodal support was found for a clade with $N$. directus, $N$. semistriatus, $N$. simulator and N. sylvaticus $(97.5 \% / 95 \%)$ and a clade with $N$. germinyi, $N$. rufipes and $N$. palustris (99.1\%/97\%). 

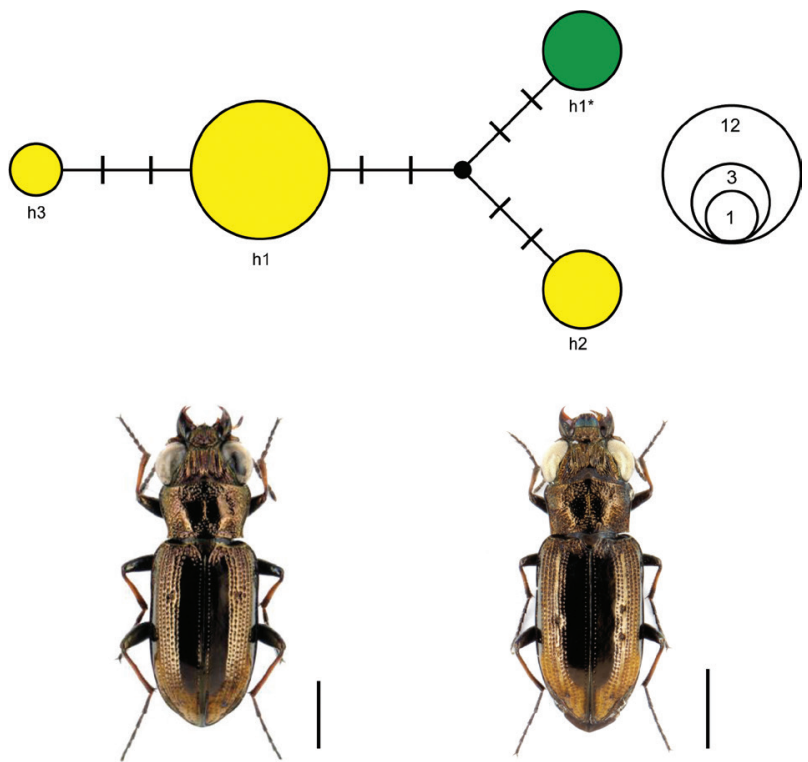

$\square$ Notiophilus biguttatus (Fabricius, 1779) $(n=16)$

Notiophilus quadripunctatus Dejean, 1826 $(n=3)$

Figure 3. Maximum statistical parsimony network of Notiophilus biguttatus (Fabricius, 1779) and Notiophilus quadripunctatus Dejean, 1828. Parameters used included default settings for connection steps, gaps being treated as fifth state. Each line represents a single mutational change, whereas small black dots indicate missing haplotypes. The numbers of analysed specimens (n) are listed and the diameter of the circles is proportional to the number of specimens for each haplotypes (see given open half circles with numbers). Scale bars $=1 \mathrm{~mm}$. Source of photos: http://www.eurocarabidae.de/ (access date: 2019-01-15).
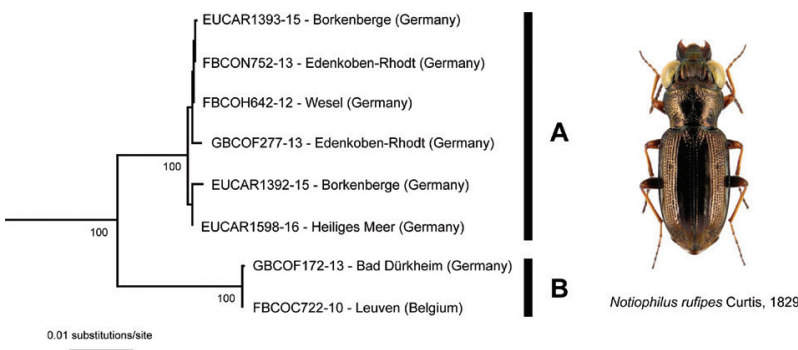

Figure 4. Subtree of the neighbour joining topology, based on Kimura 2-parameter distances of all analysed specimens of $\mathrm{No}$ tiophilus rufipes Curtis, 1829. Branches with specimen ID-number from BOLD, species names and sample localities. Numbers next to internal nodes are non-parametric bootstrap values (in $\%$ ). Source of photo: http://www.eurocarabidae.de/ (access date: $2019-01-15)$.

\section{Discussion}

For many decades, ground beetles have been used regularly as indicators of biodiversity and habitat quality (e.g. Goulet 2003, Koivula 2011, Kotze et al. 2011, Li et al. 2017). Consequently, their correct identification rep- resents a pivotal component for ecological studies and conservation planning. Our species delineation analysis demonstrated that most $(n=7,87.5 \%)$ of the analysed species of Notiophilus from Germany and Central Europe can be successfully identified by using DNA barcode sequence data and the BIN approach. This result correlates with previous barcoding studies of ground beetles (Raupach et al. 2010, Raupach et al. 2011, Pentinsaari et al. 2014, Hendrich et al. 2015, Raupach et al. 2018). Nevertheless, our analysis revealed low interspecific distances, as well as high intraspecific variability that are worthy of discussion.

Low interspecific distances were found for $N$. biguttatus and $N$. quadripunctatus (0.62\%) (Fig. 3). Based on their very similar morphology, a close relationship has been previously hypothesised (e.g. Hemmann and Trautner 2002). Both species can appear sympatric. However, only comprehensive analysis of i) more specimens sampled from various localities, ii) other faster evolving, in particular nuclear markers as microsatellites or RAD-Seqs, and iii) comprehensive morphological and morphometric studies will help to clarify if two closely related but distinct species exist or hybridisation still takes place.

In contrast to this, maximum intraspecific pairwise distances with values between 1.5 and $3.6 \%$ were found between two distinct monophyletic lineages of $N$. rufipes (Fig. 4). The collection sites of both lineages A $(n=6)$ and $\mathrm{B}(n=2)$ revealed no specific geographical pattern (Fig. 4). We also found no differences in their male genitalic characters. Based on the low number of studied specimens and the mitochondrial marker used, we are currently unable to identify factors that generate the observed variability. Examples of such factors may include: i) phylogeographic events as reported for other carabids (e.g. Zhang et al. 2006, Faille et al. 2015, Weng et al. $2016)$, ii) the presence of the maternally inherited endosymbionts such as Wolbachia (e.g. Roehrdanz and Levitan 2007, Duron et al. 2008, Werren et al. 2008, Gerth et al. 2011), or iii) the existence of cryptic species (e.g. Faille et al. 2013, Liebherr 2015, Sproul and Maddison 2017). Additional specimens from different locations have to be carefully analysed using morphological and molecular data to answer these results.

Despite the fact that only few nodes had high support values, the phylogenetic analysis revealed some important results: i) $N$. aeneus represents the sister taxon to all other analysed $N$. species, ii) all other taxa are part of two clades: one clade includes $N$. biguttatus and $N$. quadripunctatus with maximum support (100\%/100\%); all other species are found in a second clade with medium support $(87.4 \% / 85 \%)$, iii) high nodal support is shown for a clade with the closely related species of $N$. directus, $N$. semistriatus, $N$. simulator and $N$. sylvaticus and iv) high nodal support is revealed for clade with $N$. germinyi, $N$. rufipes and $N$. palustris (Fig. 5). The close relationship of $N$. directus, $N$. semistriatus, $N$. simulator and $N$. sylvaticus and the low distance values between these species (1.8 to $6.4 \%$ ) give evidence for a possible 


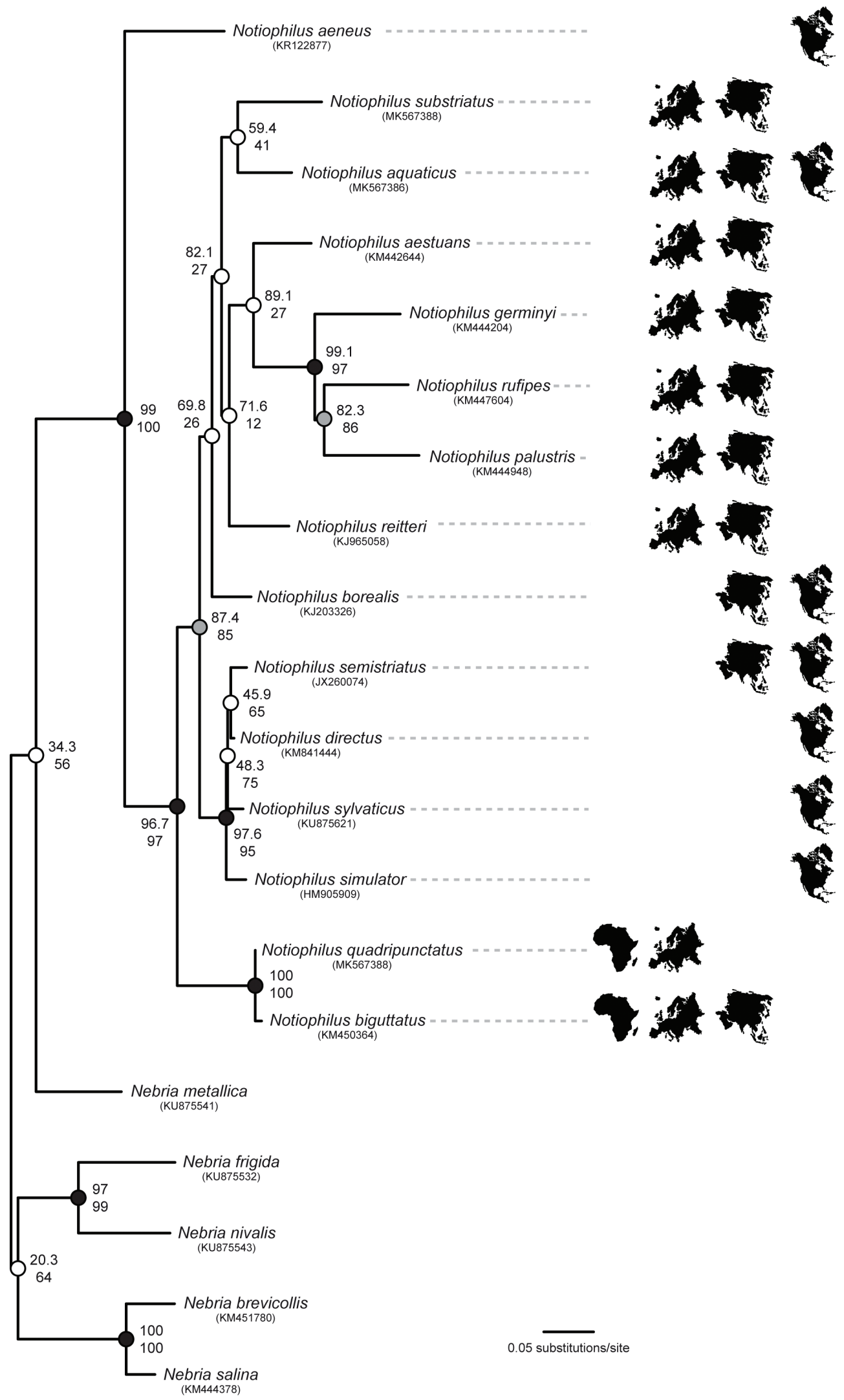

Figure 5. Maximum likelihood phylogeny inferred in IQ-TREE, based on the CO1 barcode fragment for the genus Notiophilus. The model of nucleotide substitution used was selected with Modelfinder as part of the IQ-TREE work package. The tree was rooted with five Nebria species as outgroup. Nodal support was calculated with SH-aLRT (above) and UFBoot (below) values. Black dots indicate very robust nodes with very high values (SH-aLRT $\geq 90 \%$, UFBoot $\geq 95 \%$ ), grey dots indicate moderately robust nodes (SH-aLRT $\geq 80 \%$, UFBoot $\geq 80 \%$ ) and white dots indicate weak nodes (SH-aLRT $<80 \%$, UFBoot $<80 \%$ ) (see Material and Methods for details). Continent silhouettes indicate the biogeographic distribution of the analysed taxa (from left to right: Africa, Europe, Asia and North America). 
radiation of these four species in North America (Fig. 5). If Asia represents the real hypothetical centre of origin of Notiophilus (Barševskis 2007), North America has been colonised at least two times. Interestingly, both species that were documented for Africa, are closely related. The low support values of most nodes, however, do not allow additional suggestions concerning the colonisation patterns of other regions by this genus.

\section{Conclusions}

The assessment of biodiversity using molecular tools represents an essential aspect of modern biological sciences. In this context, our dataset represents another step in building a comprehensive DNA barcoding library for carabids in Germany and Central Europe. Furthermore, a first phylogenetic analysis of this genus is presented. Although the present dataset included sequences of only 15 of the 57 known species of Notiophilus and, in particular, endemic species from Central Asia are missing, our analysis reveals some important insights into the phylogeny of this genus, including a well-supported clade of $N$. directus, N. semistriatus, N. simulator and N. sylvaticus that gives some evidence for a possible radiation of these species in North America, as well as a close relationship of $N$. germinyi, $N$. palustris and $N$. rufipes.

\section{Acknowledgements}

We would like to thank Christina Blume, Claudia Etzbauer (both ZFMK, Bonn) and Jana Deppermann (DZMB, Wilhelmshaven) for their laboratory assistance. Furthermore, we are very grateful to Sascha Buchholz (Berlin) and Frank Köhler (Bonn) for providing various beetles and to Ortwin Bleich for giving permission to use his excellent photos of ground beetles that were taken from www.eurocarabidae.de. We also thank David Kavanaugh, David Maddison and an unknown reviewer for their helpful comments. This publication was partially financed by German Federal Ministry for Education and Research (FKZ01LI1101A, FKZ01LI1101B, FKZ03F0664A), the Land Niedersachsen and the German Science Foundation (INST427/1-1), as well as by grants from the Bavarian State Government (BFB) and the German Federal Ministry of Education and Research (GBOL2: 01LI1101B). We are grateful to the team of Paul Hebert in Guelph (Ontario, Canada) for their great support and help and, in particular, to Sujeevan Ratnasingham for developing the BOLD database infrastructure and the BIN management tools. Sequencing work was partly supported by funding from the Government of Canada to Genome Canada through the Ontario Genomics Institute, whereas the Ontario Ministry of Research and Innovation and NSERC supported development of the BOLD informatics platform.

\section{References}

Anderson JM (1972) Food and feeding of Notiophilus biguttatus (Coleoptera: Carabidae). Revue de Ecologie et de Biologie du Sol 9: 177-184.

Barševskis A (2001) Notiophilus solodovnikovi sp. n. (Coleoptera: Carabidae) - new ground beetle species from Far East of Russia. Baltic Journal of Coleopterology 1: 37-40.

Barševskis A (2007) Biogeography of the genus Notiophilus Dumeril, 1806 (Coleoptera: Carabidae). Baltic Journal of Coleopterology 7: 121-135.

Barševskis A (2009) Notiophilus anichtchenkoi sp. n. (Coleoptera: Carabidae) a new ground beetle species from China. Baltic Journal of Coleopterology 9: 1-4.

Barševskis A (2011) Two new species of the genus Notiophilus Dumeril, 1806 (Coleoptera: Carabidae) from India and Afghanistan. Baltic Journal of Coleopterology 11: 127-134.

Barševskis A (2012) What do we know about Notiophilus persicus Breit, 1914 (Coleoptera: Carabidae)? Baltic Journal of Coleopterology 12: 159-166. https://doi.org/10.1007/BF00300820

Bauer T (1981) Prey capture and structure of the visual space of an insect that hunts by sight on the litter layer (Notiophilus biguttatus F., Carabidae, Coleoptera). Behavioral Ecology and Sociobiology 8: 91-97. https://doi.org/10.1007/BF00300820

Bousquet Y (2012) Catalogue of Geadephaga (Coleoptera, Adephaga) of America, north of Mexico. ZooKeys 245: 1-1722. https://doi. org/10.3897/zookeys.245.3416

Brandon-Mong GJ, Gan HM, Sing KW, Lee PS, Lim PE, Wilson JJ (2015) DNA metabarcoding of insects and allies: an evaluation of primers and pipelines. Bulletin of Entomological Research 105: 717-727. https://doi.org/10.1017/S0007485315000681

Chapman JW, Reynolds DR, Smith AD, Riley JR, Telfer MG, Woiwod IP (2005) Mass aerial migration in the carabid beetle Notiophilus biguttatus. Ecological Entomology 30: 264-272. https://doi. org/10.1111/j.0307-6946.2005.00702.x

Clement M, Posada D, Crandall KA (2000) TCS: a computer program to estimate gene genealogies. Molecular Ecology 9: 1657-1660. https://doi.org/10.1046/j.1365-294x.2000.01020.x

Collins RA, Cruickshank RH (2013) The seven deadly sins of DNA barcoding. Molecular Ecology Resources 13: 969-975. https://doi. org/10.1111/1755-0998.12046

Cristescu ME (2014) From barcoding single individuals to metabarcoding biological communities: towards an integrative approach to the study of global biodiversity. Trends in Ecology and Evolution 29: 566-571. https://doi.org/10.1016/j.tree.2014.08.001

Dai Q-Y, Gao Q, Wu C-S, Chesters D, Zhu C-D, Zhang A-B (2012) Phylogenetic reconstruction and DNA barcoding for closely related pine moth species (Dendrolimus) in China with multiple gene markers. PLoS ONE 7: e32544. https://doi.org/10.1371/journal. pone. 0032544

deWaard JR, Ivanova NV, Hajibabaei M, Hebert PDN (2008) Assembling DNA barcodes: analytical protocols. In: Martin C (Ed.) Methods in Molecular Biology: Environmental Genetics. Humana Press, Totowa, 275-293. https://doi.org/10.1007/978-1-59745-548-0_15

Duron O, Bouchon D, Boutin S, Bellamy L, Zhou L, Engelstädter J, Hurst GD (2008) The diversity of reproductive parasites among arthropods: Wolbachia do not walk alone. BMC Biology 6: 27. https:// doi.org/10.1186/1741-7007-6-27 
Edgar RC (2004) MUSCLE: a multiple sequence alignment method with reduced time and space complexity. BMC Bioinformatics 5: 113. https://doi.org/10.1186/1471-2105-5-113

Ernsting G, Mulder AJ (1981) Components of predatory behavior underlying density-dependent prey-size selection by Notiophilus biguttatus F. (Carabidae, Coleoptera). Oecologia 51: 169-174. https:// doi.org/10.1007/BF00540596

Ernsting G, Isaaks JA, Berg MP (1992) Life cycle and food availability indices in Notiophilus biguttatus (Coleoptera, Carabidae). Ecological Entomology 17: 33-42. https://doi.org/10.1111/j.1365-2311.1992. tb01036.x

Faille A, Deliot P, Queinnec E (2013) A new cryptic species of Aphaenops (Coleoptera: Carabidae: Trechinae) from a French Pyrenean cave: Congruence between morphometrical and geographical data confirm species isolation. Annales de la Société entomologique de France (N.S.) 43: 363-370. https://doi.org/10.1080/00379271.2007.10697533

Faille A, Tänzler R, Toussaint EFA (2015) On the way to speciation: Shedding light on the Karstic phylogeography of the microendemic cave beetle Aphaenops cerberus in the Pyrenees. Journal of Heredity 106: 692-699. https://doi.org/10.1093/jhered/esv078

Felsenstein J (1985) Confidence limits on phylogenies: an approach using the bootstrap. Evolution 39: 783-791. https://doi. org/10.2307/2408678

Gerth M, Geißler A, Bleidorn C (2011) Wolbachia infections in bees (Anthophila) and possible implications for DNA barcoding. Systematics and Biodiversity 9: 319-327. https://doi.org/10.1080/147 72000.2011 .627953

Goldstein PZ, DeSalle R (2010) Integrating DNA barcode data and taxonomic practice: determination, discovery, and description. Bioessays 33: 135-147. https://doi.org/10.1002/bies.201000036

Goetze E (2003) Cryptic speciation on the high seas; global phylogenetics of the copepod family Eucalanidae. Proceedings of the Royal Society of London B: Biological Sciences 270: 2321-2331. https:// doi.org/10.1098/rspb.2003.2505

Goulet H (2003) Biodiversity of ground beetles (Coleoptera: Carabidae) in Canadian agricultural soils. Canadian Journal of Soil Science 83: 259-264. https://doi.org/10.4141/S01-061

Greenstone MH, Rowley DL, Heimbach U, Lundgren JG, Pfannenstiel RS, Rehner SA (2005) Barcoding generalist predators by polymerase chain reaction: carabids and spiders. Molecular Ecology 14: 3247-3266. https://doi.org/10.1111/j.1365-294X.2005.02628.x

Guindon S, Dufayard J-F, Lefort V, Anisimova M, Hordijk W, Gascuel O (2010) New algorithms and methods to estimate maximum-likelihood phylogenies: assessing the performance of PhyML 3.0. Systematic Biology 59: 307-321. https://doi.org/10.1093/sysbio/syq010

Hannig K (2005) Beispiele zur Variabilität von morphologischen Merkmalen und Zeichnungsmustern bei einheimischen Laufkäfern (Coleoptera, Carabidae). Mitteilungen der Arbeitsgemeinschaft der Rheinischen Koleopterologen (Bonn) 15: 45-48. [In German]

Hausmann A, Haszprunar G, Hebert PDN (2011) DNA barcoding the geometrid fauna of Bavaria (Lepidoptera): successes, surprises, and questions. Public Library of Science ONE 6: e17134. https://doi. org/10.1371/journal.pone.0017134

Havemann N, Gossner MM, Hendrich L, Morinière J, Niedringhaus R, Schäfer P, Raupach MJ (2018) From water striders to water bugs: The molecular diversity of aquatic Heteroptera (Gerromorpha, Nepomorpha) of Germany based on DNA barcodes. PeerJ 6: e4577. https://doi.org/10.7717/peerj.4577
Hebert PDN, Cywinska A, Ball SL, deWaard JR (2003a) Biological identifications through DNA barcodes. Proceedings of the Royal Society of London Series B: Biological Sciences 270: 313-321. https:// doi.org/10.1098/rspb.2002.2218

Hebert PDN, Ratnasingham S, deWaard JR (2003b) Barcoding animal life: cytochrome $c$ oxidase subunit 1 divergences among closely related species. Proceedings of the Royal Society of London Series B: Biological Sciences 270: S96-S99. https:/doi.org/10.1098/ rsbl.2003.0025

Heijermann T, Aukema B (2014) Notiophilus quadripunctatus weer terug op de Nederlandse lijst (Coleoptera: Carabidae). Entomologische Berichten 74: 143-146. [In Dutch]

Hemmann K, Trautner J (2002) Notiophilus quadripunctatus Dejean, 1826 neu in Deutschland. Angewandte Carabidologie 4/5: 117-120. [In German]

Hendrich L, Morinière J, Haszprunar G, Hebert PDN, Hausmann A, Köhler F, Balke M (2015) A comprehensive DNA barcode database for Central European beetles with a focus on Germany: Adding more than 3,500 identified species to BOLD. Molecular Ecology Resources 15: 795-818. https://doi.org/10.1111/1755-0998.12354

Hoang DT, Chernomor O, von Haeseler A, Minh BQ, Vinh LS (2018) UFBoot2: Improving the ultrafast bootstrap approximation. Molecular Biology and Evolution 35: 518-522. https://doi.org/10.1093/ $\mathrm{molbev} / \mathrm{msx} 281$

Ivanova NV, deWaard JR, Hebert PDN (2006) An inexpensive, automation-friendly protocol for recovering high-quality DNA. Molecular Ecology Notes 6: 998-1002. https://doi.org/10.1111/j.14718286.2006.01428.x

Kalyaanamoorthy S, Minh BQ, Wong TKF, von Haeseler A, Jermiin LS (2017) ModelFinder: Fast model selection for accurate phylogenetic estimates. Nature Methods 14: 587-589. https://oi.org/10.1038/ nmeth. 4285

Kearse M, Moir R, Wilson A, Sone-Havas S, Cheung M, Sturrock S, Buxton S, Cooper A, Markowitz S, Duran C, Thierer T, Ashton B, Meintjes P, Drummond A (2012) Geneious Basic: an integrated and extendable desktop software platform for the organization and analysis of sequence data. Bioinformatics 15: 1647-1649. https://doi. org/10.1093/bioinformatics/bts199

Kimura M (1980) A simple method for estimating evolutionary rates of base substitutions through comparative studies of nucleotide sequences. Journal of Molecular Evolution 16: 111-120. https://doi. org/10.1007/BF01731581

Klopfstein S, Kropf C, Quicke DLJ (2010) An evaluation of phylogenetic informativeness profiles and the molecular phylogeny of Diplazontinae (Hymenoptera, Ichneumonidae). Systematic Biology 59: 226-241. https://doi.org/10.1093/sysbio/syp105

Koivula MJ (2011) Useful model organisms, indicators, or both? Ground beetles (Coleoptera, Carabidae) reflecting environmental conditions. ZooKeys 100: 287-317. https://doi.org/10.3897/zookeys.100.1533

Kotze DJ, Brandmayr P, Casale A, Dauffy-Richard E, Dekoninck W, Koivula MJ, Lövei GL, Mossakowski D, Noordijk J, Paarmann W, Pizzolotto R, Saska P, Schwerk A, Serrano J, Szyszko J, Taboada A, Turin H, Venn S, Vermeulen R, Zetto T (2011) Forty years of carabid beetle research in Europe - from taxonomy, biology, ecology and population studies to bioindication, habitat assessment and conservation. In: Kotze DJ, Assmann T, Noordijk J, Turin H, Vermeulen R (Eds) Carabid Beetles as Bioindicators: Biogeographical, Ecological and Environmental Studies. ZooKeys 100: 55-148. https://doi.org/10.3897/zookeys.100.1523 
Kumar S, Stecher G, Knyaz C, Tamura K (2018) MEGA X: Molecular Evolutionary Genetics Analysis across computing platforms. Molecular Biology and Evolution 35: 1547-1549. https://doi.org/10.1093/ molbev/msy096

Leigh JW, Bryant D (2015) POPART: Full-feature software for haplotype network construction. Methods in Ecology and Evolution 6: 1110-1116. https://doi.org/10.1111/2041-210X.12410

Li W-B, Liu N-Y, Wu Y-H, Zhang Y-C, Xu Q, Chu J, Wang S-Y, Fang J (2017) Community composition and diversity of ground beetles (Coleoptera: Carabidae) in Yaoluoping National Nature Reserve. Journal of Insect Science 17: 114. https://doi.org/10.1093/jisesa/iex081

Liebherr JK (2015) The Mecyclothorax beetles (Coleoptera, Carabidae, Moriomorphini) of Haleakala-, Maui: Keystone of a hyperdiverse Hawaiian radiation. ZooKeys 544: 1-407. https://doi.org/10.3897/ zookeys.544.6074

Lindroth CH (1961-1969) The ground-beetles (Carabidae, excl. Cicindelinae) of Canada and Alaska. Parts 1-6. Opuscula Entomologica Supplementa XX, XXIV, XXIX, XXXIII, XXXIV, XXXV.

Lindroth CH (1985) The Carabidae (Coleoptera) of Fennoscandia and Denmark. Fauna Entomologica Scandinavica 15 Part 1: 1-225.

Löbl I, Löbl D (2017) Catalogue of Palaearctic Coleoptera - Volume 1, revised and updated edition. Archostemata - Myxophaga - Adephaga. Brill, Leiden - Boston, 1477 pp. https://doi. org/10.1163/9789004330290

Lorenz W (2005) Systematic list of extant beetles of the world: Insecta Coleoptera "Geadephaga": Trachypachidae and Carabidae inc. Paussina, Cicindelinea, Rhysodinae. Lorenz, Tutzing, 530 pp.

Maddison DR (2008) Systematics of the North American beetle subgenus Pseudoperyphus (Coleoptera: Carabidae: Bembidion) based upon morphological, chromosomal, and molecular data. Annals of Carnegie Museum 77: 147-193. https://doi.org/10.2992/0097-446377.1.147

Maddison WP, Li D, Bodner M, Zhang J, Xu X, Liu Q, Liu F (2014) The deep phylogeny of jumping spiders (Araneae, Salticidae). ZooKeys 440: 57-87. https://doi.org/10.3897/zookeys.440.7891

Matzen da Silva J, dos Santos A, Cunha MR, Costa FO, Creer S, Carvalho GR (2011) Multigene molecular systematics confirm species status of morphologically convergent Pagurus hermit crabs. PLoS ONE 6: e28233. https://doi.org/10.1371/journal.pone.0028233

Minh BQ, Nguyen MAT, von Haeseler A (2013) Ultrafast approximation for phylogenetic bootstrap. Molecular Biology and Evolution 30: 1188-1195. https://doi.org/10.1093/molbev/mst024

Müller-Motzfeld G (2006) Bd. 2, Adephaga 1: Carabidae (Laufkäfer). In: Freude H, Harde KW, Lohse GA, Klausnitzer B (Eds) Die Käfer Mitteleuropas. Spektrum-Verlag, Heidelberg/Berlin, 521 pp. [In German]

Nguyen L-T, Schmidt HA, von Haeseler A, Minh BQ (2015) IQ-TREE: A fast and effective stochastic algorithm for estimating maximum likelihood phylogenies. Molecular Biology and Evolution 32: 268274. https://doi.org/10.1093/molbev/msu300

Morinière J, Hendrich L, Hausmann A, Hebert PDN, Haszprunar G, Gruppe A (2014) Barcoding Fauna Bavarica: 78\% of the Neuropteroida fauna barcoded! Public Library of Science ONE 9: e109719. https://doi.org/10.1371/journal.pone.0109719

Park D-S, Footit RG, Maw E, Hebert PDN (2011) Barcoding bugs: DNA-based identification of the true bugs (Insecta: Hemiptera: Heteroptera). Public Library of Science ONE 6: e18749. https://doi. org/10.1371/journal.pone.0018749
Pentinsaari M, Hebert PDN, Mutanen M (2014) Barcoding beetles: a regional survey of 1872 species reveals high identification success and unusually deep interspecific divergences. Public Library of Science ONE 9: e108651. https://doi.org/10.1371/journal.pone.0108651

Porter TM, Hajibabaei M (2018) Scaling up: A guide to high-throughput genomic approaches for biodiversity analysis. Molecular Ecology 27: 313-338. https://doi.org/10.1111/mec.14478

Ratnasingham S, Hebert PDN (2007) BOLD: The Barcode of Life Data Systems. Molecular Ecology Notes 7: 355-364. https://doi. org/10.1111/j.1471-8286.2007.01678.x

Ratnasingham S, Hebert PDN (2013) A DNA-based registry for all animal species: the Barcode Index Number (BIN) system. Public Library of Science ONE 8: e66213. https://doi.org/10.1371/journal. pone. 0066213

Raupach MJ, Astrin JJ, Hannig K, Peters MK, Stoeckle MY, Wägele JW (2010) Molecular species identifications of Central European ground beetles (Coleoptera: Carabidae) using nuclear rDNA expansion segments and DNA barcodes. Frontiers in Zoology 7: 26. https://doi.org/10.1186/1742-9994-7-26

Raupach MJ, Hannig K, Moriniére J, Hendrich L (2016) A DNA barcode library for ground beetles (Insecta: Coleoptera: Carabidae) of Germany: The genus Bembidion Latreille, 1802 and allied taxa. ZooKeys 592: 121-141. https://doi.org/10.3897/zookeys.592.8316

Raupach MJ, Hannig K, Moriniére J, Hendrich L (2018) A DNA barcode library for ground beetles of Germany: The genus Amara Bonelli, 1810 (Insecta: Coleoptera: Carabidae). ZooKeys 759: 5780. https://doi.org/10.3897/zookeys.759.24129

Roehrdanz RL, Levitan E (2007) Wolbachia bacterial infections linked to mitochondrial DNA reproductive isolation among populations of Northern corn rootworms (Coleoptera: Chrysomelidae). Annals of the Entomological Society of America 100: 522-531. https://doi. org/10.1603/0013-8746(2007)100[522:WBILTM]2.0.CO;2

Saitou N, Nei M (1987) The neighbor-joining method: a new method for reconstructing phylogenetic trees. Molecular Biology and Evolution 4: 406-425. https://doi.org/10.1093/oxfordjournals.molbev. a040454

Sproul JS, Maddison DR (2017) Cryptic species in the mountaintops: species delimitation and taxonomy of the Bembidion breve species group (Coleoptera: Carabidae) aided by genomic architecture of a century-old type specimen. Zoological Journal of the Linnean Society 183: 556-583. https://doi.org/10.1093/zoolinnean/zlx076

Schmidt S, Schmid-Egger C, Morinière J, Haszprunar G, Hebert PDN (2015) DNA barcoding largely supports 250 years of classical taxonomy: identifications for Central European bees (Hymenoptera, Apoidea partim) Molecular Ecology Resources 15: 985-1000. https://doi.org/10.1111/1755-0998.12363

Steel MA, Lockhart PJ, Penny D (1993) Confidence in evolutionary trees from biological sequence data. Nature 364: 440-442. https:// doi.org/10.1038/364440a0

Trautner J, Fritze M-A, Hannig K, Kaiser M (2014) Distribution Atlas of Ground Beetles in Germany. Books on Demand, Norderstedt, 348 pp.

Weng Y-M, Yang M-M, Yeh W-B (2016) A comparative phylogeographic study reveals discordant evolutionary histories of alpine ground beetles (Coleoptera, Carabidae). Ecology and Evolution 6: 2061-2073. https://doi.org/10.1002/ece3.2006

Wetzer R (2002) Mitochondrial genes and isopod phylogeny. Journal of Crustacean Biology 22: 1-14. https://doi.org/10.1163/2002197599990204 
Werren JH, Baldo L, Clark ME (2008) Wolbachia: master manipulators of invertebrate biology. Nature Reviews 6: 741-751. https://doi. org/10.1038/nrmicro1969

Will KW, Rubinoff D (2004) Myth of the molecule: DNA barcodes for species cannot replace morphology for identification and classification. Cladistics 20: 47-55. https://doi.org/10.1111/j.10960031.2003.00008.x

Woodcock TS, Boyle EE, Roughley RE, Kevan PG, Labbee RN, Smith ABT, Goulet H, Steinke D, Adamowicz SJ (2013) The diversity and biogeography of the Coleoptera of Churchill: insights from DNA barcoding. BMC Ecology 13: 40. https://doi.org/10.1186/1472-6785-13-40

Xia X (2009) Assessing substitution saturation with DAMBE. In: Lemey P, Salemi M, Vandamme A-M (Eds) The Phylogenetic Handbook. $2^{\text {nd }}$ Edition. Cambridge University Press, Cambridge, 615630. https://doi.org/10.1017/CBO9780511819049.022

Xia X (2018) DAMBE7: New and improved tools for data analysis in molecular biology and evolution. Molecular Biology and Evolution 35: 1550-1552. https://doi.org/10.1093/molbev/msy073

Xia XH, Xie Z, Salemi M, Chen L, Wang Y (2003) An index of substitution saturation and its application. Molecular Phylogenetics and Evolution 26: 1-7. https://doi.org/10.1016/S1055-7903(02)00326-3

Yu DW, Ji Y, Emerson BC, Wang X, Ye C, Yang C, Ding Z (2012) Biodiversity soup: metabarcoding of arthropods for rapid biodiversity assessment and biomonitoring. Methods in Ecology and Evolution 3: 613-623. https://doi.org/10.1111/j.2041-210X.2012.00198.x

Zhang A-B, Kubota K, Takami Y, Kim JL, Kim JK, Sota T (2006) Comparative phylogeography of three Leptocarabus ground beetle species in South Korea, based on the mitochondrial COI and nucle- ar 28S rRNA genes. Zoological Science 23: 745-754. https://doi. org/10.2108/zsj.23.745

\section{Supplementary material 1 \\ Detailed Neighbour Joining topology}

Authors: Michael J. Raupach, Karsten Hannig, Jérome Morinière, Lars Hendrich

Data type: Neighbour Joining topology

Copyright notice: This dataset is made available under the Open Database License (http://opendatacommons.org/licenses/odbl/1.0/). The Open Database License (ODbL) is a license agreement intended to allow users to freely share, modify, and use this Dataset while maintaining this same freedom for others, provided that the original source and author(s) are credited.

Link: https://doi.org/10.3897/dez.66.34711.suppl1

\section{Supplementary material 2}

Substitution saturation plot

Authors: Michael J. Raupach, Karsten Hannig, Jérome Morinière, Lars Hendrich

Data type: Substitution saturation plot

Copyright notice: This dataset is made available under the Open Database License (http://opendatacommons.org/licenses/odbl/1.0/). The Open Database License (ODbL) is a license agreement intended to allow users to freely share, modify, and use this Dataset while maintaining this same freedom for others, provided that the original source and author(s) are credited.

Link: https://doi.org/10.3897/dez.66.34711.suppl2 